\title{
ON THE ROLE OF MODAL INTUITION IN MODAL LOGIC
}

\section{Introduction}

The philosophy of alethic, as opposed to deontic or epistemic, metaphysical modality studies the logic, semantics, metaphysical, and epistemic issues pertaining to modal statements. A statement of alethic modality contains either the phrase 'it could have been the case that' or the phrase 'it could not have been the case that', or some linguistic variant, such as 'it is possible that' or 'it is impossible that'. In the philosophy of modality the central goal is to: (a) find the correct logical codification of alethic modality, (b) the valid rules of modal reasoning, and (c) the correct formal semantical treatment of modal statements that does not commit us ontologically to entities or theses about objects and properties that are unacceptable, given our other commitments. Finally, a comprehensive treatment includes: (d) an account of how we know or can come to be justified in believing any number of modal claims.

One of the most important advances in the philosophy of modality was the introduction of Kripke-style semantics for propositional modal logic by Saul Kripke. The model he introduced relies on a set of possible worlds W, a distinguished actual world @, and a binary accessibility relation $R$ defined on $\mathrm{W}$. It is necessary that $\mathrm{P}, ~ ' \square \mathrm{P}$ ', is true at a world $w$ just in case $\mathrm{P}$ is true at every world accessible from $w$. It is possible that $\mathrm{P}$, ' $\diamond \mathrm{P}$ ', is true at a world $w$ just in case $\mathrm{P}$ is true at some world accessible from $w$. The following axioms and conditions characterize various ways in which one can understand the space of possible worlds via the accessibility relation. The four axioms conjoined constitute the $\mathrm{S}_{5}$ system of propositional modal logic.

$\mathrm{K}: \square(\mathrm{P} \rightarrow \mathrm{Q}) \rightarrow(\square \mathrm{P} \rightarrow \square \mathrm{Q}) \quad$ Normal / Distribution

$\mathrm{T}: \square \mathrm{P} \rightarrow \mathrm{P}$

Reflexive: $\forall w_{\mathrm{i}}\left[w_{i} \mathrm{R} w_{\mathrm{i}}\right]$

$\mathrm{B}^{1}: \diamond \square \mathrm{P} \rightarrow \mathrm{P}$

$\mathrm{S}_{4}: \square \mathrm{P} \rightarrow \square \square \mathrm{P}$

Symmetric: $\forall w_{\mathrm{i}} \forall w_{\mathrm{j}}\left[w_{\mathrm{i}} \mathrm{R} w_{\mathrm{j}} \rightarrow w_{\mathrm{i}} \mathrm{R} w_{\mathrm{j}}\right]$

Transitive: $\forall w_{\mathrm{i}} \forall w_{\mathrm{j}} \forall w_{\mathrm{k}}\left[\left(w_{\mathrm{i}} \mathrm{R} w_{\mathrm{j}} \wedge w_{j} \mathrm{R} w_{k}\right) \rightarrow\left(w_{\mathrm{i}} \mathrm{R} w_{\mathrm{k}}\right)\right]$

The conjunction of the $\mathrm{T}, \mathrm{B}$, and $\mathrm{S}_{4}$ axioms can be captured through the characteristic axiom of the $\mathrm{S}_{5}$ system.

$\mathrm{E}^{2}: \diamond \square \mathrm{P} \rightarrow \square \mathrm{P} \quad$ Equivalence (Reflexive, Symmetric, and Transitive)

1 Another way of presenting B is: $\mathrm{P} \rightarrow \square \diamond \mathrm{P}$.

2 Another way of presenting $\mathrm{E}$ is: $\diamond \mathrm{P} \rightarrow \square \diamond \mathrm{P}$. 
Some philosophers, such as Williamson (2013), find the $S_{5}$ system to be the most satisfying account of logical and metaphysical modality. However, some do not.

Salmon (1989) argues that the proposition $(\mathrm{V})$ is a counterexample to the $\mathrm{S}_{4}$ axiom of modal logic.

V: A table $t$, which actually originated from a hunk of matter $\mathrm{M}$ carved from a tree $\mathrm{T}$ could have originated from $\mathrm{M}^{*}$, a portion of wood carved from $\mathrm{T}$ that is just slightly different from $\mathrm{M}$.

Dummett (1993) argues that the proposition (U) is a counterexample to the B axiom of modal logic.

$\mathrm{U}$ : There could have been unicorns.

Moving off of the work of Salmon and Dummett: Vaidya (2008) argues that Salmon's counterexample to $S_{4}$ is plausible and can be extended into the discourse of debates over the epistemology of modality, and Lee Walters (2014) argues that Dummett's counterexample to B fails, but the counterexample can be deployed as a successful counterexample to the $\mathrm{E}$ axiom.

In what follows I will develop a version of, what I call, the DummettWalters argument against $\mathrm{S}_{5}{ }^{3}$. I will use the Dummett-Walters argument as well as the Salmon-Vaidya argument to explore an important question in the philosophy of modality that pertains to the interaction between modal logic and modal intuition: How should theories of modal logic interact with potential counterexamples based on modal intuition? I will argue that within the philosophy of modality there is a tension that borders on paradox when we go about exploring potential counterexamples to axioms of modal logic. Here is an introductory sketch of the tension. On the one hand, there are modal intuitions, intuitions whose content is modal, which can be deployed to challenge certain axioms of modal logic, such as $\mathrm{B}$ and $\mathrm{S}_{4}$. On the other hand, concerning these modal intuitions one might ask: how do we know that these modal intuitions are in fact tracking modal reality, as opposed to being mere modal illusions produced by our own individual modal biases?

The problem can also be stated as follows: if we cannot have any confidence in a certain range of modal intuitions, why should we trust them in providing us with reasons to reject or accept specific systems of modal logic? This issue can be made more problematic by introducing the distinction, also discussed by van Inwagen (1998), between ordinary and extraordinary modal intuitions. If a counterexample to an axiom of modal logic rests on an ordinary modal intuition, then perhaps we have good grounds for rejecting an axiom that is contrary to the ordinary modal intuition. However, and more problematically: should we be equally confident in rejecting an axiom of modal logic when the counterexample it rests on relies on an extraordinary modal intuition?

In exploring the significance of this question I will argue that on two leading theories, Chalmers's (2002) conceivability-based account, and Williamson's

3 It is important to note that Walters' own clarification of Dummett's argument does not involve a commitment to the truth of $\mathrm{U}$, nor to the additional assumptions that are required for the counterexample to go through. As Walters' notes at the end of his paper, Dummett's argument requires one accepting several claims. 
(2007) counterfactual-based account, the intuitions against $S_{4}$ and $S_{5}$ are highly problematic. Were the modal intuitions against $S_{4}$ and $S_{5}$ known on the basis of either of these views, they would provide evidence against the views, thus undermining their own potential role in serving as counterexamples to $S_{4}$ or $S_{5}$. Thus, we are left with the question: how do these intuitions acquire a sufficiently strong enough epistemic status so as to serve as a counterexample to the axioms of modal logic that they are deployed against?

In 2 I will develop the Dummett-Walters argument against $S_{5}$, and bring it into contact with the Salmon-Vaidya argument against $\mathrm{S}_{4}$. In $3 \mathrm{I}$ will develop what I call the paradox of modal logic and modal intuition. In 4 I will consider a response to the paradox based on Goodman's account of reflective equilibrium for the case of logic. In particular, I will address a well-known question within the literature on reflective equilibrium concerning the role of intuitions as inputs. The question is: Which intuitions matter? With respect to this question I will attempt to draw a provisional distinction between ordinary and extraordinary modal intuitions. I will defend a conservative approach to selecting a modal logic based on modal intuition, on this approach only ordinary modal intuitions matter. Finally, in $\mathbf{5}$ I will close by discussing the relevance of restricting the use of modal intuitions to ordinary modal intuitions as it pertains to Williamson's (2014) defense of the counterintuitive thesis of necessitism, on which necessarily everything is necessarily something.

\section{Counterexamples to Axioms of Modal Logic}

\section{Dummett-Walters}

After explaining Dummett's purported counterexample to the B axiom and how Dummett tentatively extends it $S_{4}$, Walters argues that the counterexample to $B$ fails, but that it succeeds as a counterexample to $S_{5}$.

What actually follows [from Dummett's example] is that $S_{5}$ is to be rejected. Let us call the proposition that Dummett is concerned with ' $\mathrm{P}$.' Dummett claims that $\mathrm{P}$ is necessarily true in $\mathrm{u}$, so that at $w$ we have $\diamond \square \mathrm{P}$. He also claims that this proposition is possibly false in $w$, namely, $\diamond \neg$ P. But what follows from the conjunction of $\diamond \square \mathrm{P} \wedge \diamond \neg \mathrm{P}$ is the falsity of $\mathrm{E}: \diamond \square \mathrm{P} \rightarrow \square \mathrm{P}$. (Walters 2014: 4)

Because I am not engaging the question of whether Dummett's counterexample is a counterexample to B, I will not engage the excellent work done by Walters in showing that it is not a counterexample to B. Rather, I will go on to simply generate the Dummett-Walters argument against $\mathrm{S}_{5}$.

Let $w$ be the actual world.

Let $\mathrm{P}$ be the statement: there are unicorns.

Dummett holds, contrary to Kripke, that in $w$ : both $\diamond \mathrm{P}$ and $\neg_{\neg} \mathrm{P}$ hold.

Let $u$ be a world in which there are creatures resembling the unicorns of the myth, which belong, like deer, to the order Artiodactyla. 
Let $v$ be a world in which there are creatures resembling the unicorns of the myth, which belong, like horses, to the order Perissodactyla.

Necessity of Order Membership, NOM: Where $x$ ranges over species, if $x$ belongs to order $\Phi$, then $x$ belongs to $\Phi$ essentially, and, since what is essentially true of $x$ is necessarily true of $x$, it follows that $\square \Phi x$.

Let: $F=$ the order Artiodactyla

Let: $G=$ the order Perissodactyla:

From the description of $u, v$, and NOM, it follows that

Fx holds in $u$.

G $x$ holds in $v$.

The Dummett-Walters argument is the following:

1. In the actual world $w$ : $\succ_{\neg \mathrm{P}}$ and $\diamond \mathrm{P}$ are true, since although there are no unicorns in the actual world, that is $\neg \mathrm{P}$ is true in $w$, it is possible that there are unicorns and possible that there are not unicorns. In other words, Dummett holds, contrary to Kripke, that from the actual world the statement that there could have been unicorns is true and that there might not have been unicorns is true.

2. $\square \mathrm{P}$ is true in $u$, since in $u$ there are creatures resembling unicorns, which are of the order Artiodactyla, and by the necessity of order membership, being of the order Artiodactyla is essential to all creatures that are of the order.

3. $\diamond \square \mathrm{P}$ is true in $w$, since $u$ is accessible from $w$, and in $u$ : $\square \mathrm{P}$ is true. $\therefore$

4. $\diamond \square \mathrm{P} \wedge \diamond \neg \mathrm{P}$ is true in $w$, from (3) and (1) by conjunction. $\therefore$

5. $\diamond \square \mathrm{P} \wedge \neg \square \mathrm{P}$ is true in $w$, from (4) and the equivalence of $\neg \square \mathrm{P}:: \diamond \neg \mathrm{P}$. $\therefore$

6. $\neg[\diamond \square \mathrm{P} \rightarrow \square \mathrm{P}]$ is true in $w$, from the equivalence of $[\Phi \wedge \neg \Psi]:: \neg[\Phi \rightarrow \Psi]$.

The counterexample can also be captured through the following diagram:

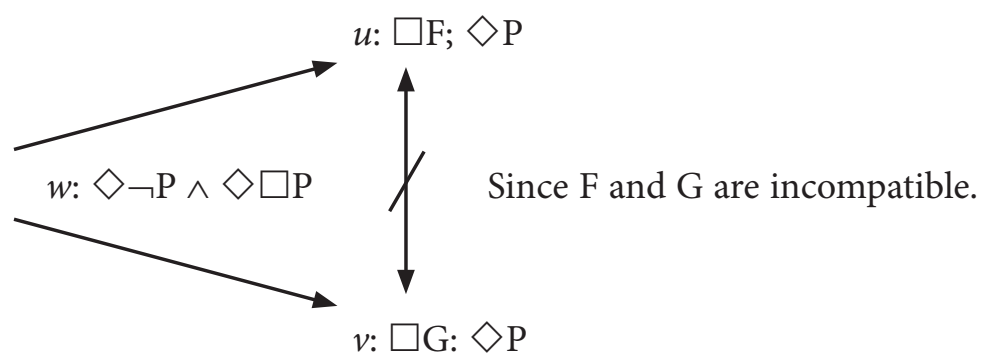


Walters articulates in words what is presented in the possible worlds diagram above. His remarks capture the core point of the argument, as well as the open question as to which axiom is at fault for the failure.

Now, given that both $u$ and $v$ are accessible from the actual world, $w$, the mutual inaccessibility of $u$ and $v$ shows only that the accessibility relation cannot be both symmetric and transitive, which is to say $S_{5}$ must go. ... So, if we accept Dummett's case, then for all that has been said so far, it could be that transitivity and $\mathrm{S}_{4}$ are to be given up, rather than symmetry and B. (Walters 2014: 4)

\section{Salmon-Vaidya ${ }^{4}$} axiom.

Vaidya (2008) articulates a version of Salmon's (1989) counterexample to the $S_{4}$

Essentiality of Origin, (EO): If $\Phi$ is the origin of $x$, then in every possible world in which $x$ exists, it $\Phi x$ is essential, and thus $\square \Phi x$ is true.

$\mathrm{V}$ : A table $t$, which actually originated from a hunk of matter $\mathrm{M}$ carved from a tree $\mathrm{T}$ could have originated from $\mathrm{M}^{\star}$, a portion of wood carved from $\mathrm{T}$ that is just slightly different from $\mathrm{M}$.

The Salmon-Vaidya argument

1. $\mathrm{M} t$ is an actual world fact.

$\therefore$

2. $\square \mathrm{M} t$, from (1) and (EO).

3. V from modal intuition grounded in the view that social kinds, as opposed to biological kinds, can tolerate vagueness at their origins.

4. $\diamond \diamond \neg \mathrm{M} t$, since $\mathrm{V}$ grounds $\diamond \mathrm{M}^{\star} t$.

$\therefore$

5. $\neg \square \square \mathrm{M} t$, from 4 and $\square / \neg \diamond \neg$ equivalence.

$\therefore$

6. $\square \mathrm{M} t \wedge \neg \square \square \mathrm{M}$. from (2) and (5) by conjunction $\therefore$

7. $\neg[\square \mathrm{M} t \rightarrow \square \square \mathrm{M} t]$, from (6) and the equivalence of $[\Phi \wedge \neg \Psi]: \because \neg[\Phi \rightarrow$ $\Psi]$.

The core idea of the argument comes from $\mathrm{V}$. If the material origin $\mathrm{M}$, which comes from tree $\mathrm{T}$, of table $t$ can tolerate vagueness, then it follows that although $t$ has it origin in $\mathrm{M}$ essentially, it is possibly possible that $t$ originated from $\mathrm{M}^{\star}$, a portion of $\mathrm{T}$ just slightly different from $\mathrm{M}$.

\section{Counterexamples and Questions}

The counterexample to $S_{5}$ offered by the Dummett-Walters argument rests on U: There could have been unicorns.

4 What is presented here is nothing more than Salmon (1989). The core of the extension of Salmon's (1989) argument by Vaidya occurs in deploying it as a potential problem for Chalmers (2002) conceivability-based theory of the epistemology of modality. 
The counterexample to $\mathrm{S}_{4}$ offered by the Salmon-Vaidya argument rests on

$\mathrm{V}$ : A table $t$, which actually originated from a hunk of matter $\mathrm{M}$ carved from a tree $\mathrm{T}$ could have originated from $\mathrm{M}^{*}$, a portion of wood carved from $\mathrm{T}$ that is just slightly different from $\mathrm{M}$.

In light of $\mathrm{V}$ and $\mathrm{U}$, and the fact that $\mathrm{S}_{5} \rightarrow \mathrm{S}_{4}$, we can formulate the following normative question:

$\mathrm{M}$ : Should we reject $\mathrm{S}_{5}$ on the basis of $\mathrm{V}$ and $\mathrm{U}$ ?

$\mathrm{V}$ and $\mathrm{U}$ are both modal statements. Each is a claim to the effect that something is possible. $U$ concerns the possibility of a kind of entity, which does not exist in the actual world, existing in some other possible world. V concerns the interaction of vagueness with modality with respect to the origins of a material social kind. Some people have the intuition that both are true. But how seriously should we take these propositions in thinking about selecting a modal logic? I believe that we cannot consider $\mathrm{M}$ without also engaging the epistemic question:

$\mathrm{J}$ : How can we be justified in believing (or gaining knowledge of) $\mathrm{V}$ and $\mathrm{U}$ ?

Moreover, consideration of $\mathrm{V}$ and $\mathrm{U}$ and the consequences they potentially have on axioms of modal logic leads us directly to questions concerning the epistemology of modality. The general view is that the philosophy of modality, including its semantics, metaphysics, epistemology, and logic, must be confronted together.

\section{The Paradox of Modal Logic and Modal Intuition}

The epistemology of modality is concerned with the question: how can we know or be justified in believing that a modal proposition is true? The epistemology of modality is thought of as a special area of inquiry because prima facie it appears that we can know (i) that something that is not actually true, could have been true, and (ii) something which is true, is also necessarily true. Knowledge of type (i) and type (ii) prima facie outstrips what knowledge of the actual world provides us with, since non-actual possibilities are true in some possible world distinct from the actual world and necessities are true in all possible worlds. There are many accounts of how we can come to know what is merely possible or necessary. In recent work, however, there are two important and well-developed accounts:

Chalmers's (2002) Modal rationalism, MR.

MR:Ideal Primary Positive Conceivability entails Primary Possibility.

$\&$

Williamson's (2007) counterfactual-guide, CG.

CG: $\diamond \mathrm{P} \rightarrow \neg\left[\mathrm{P} \rightarrow_{\mathrm{c}} \perp\right]$, If it is possible that $\mathrm{P}$, then it is not the case that were $\mathrm{P}$ true a contradiction would follow.

How would each of these views account for $\mathrm{V}$ and $\mathrm{U}$ ? 
On MR the basic idea is that an agent can conceive of a situation in which $\mathrm{V}$ is true, and $\mathrm{U}$ is true, and that this conceivability provides at least some justification for believing that $\mathrm{U}$ and $\mathrm{V}$ are true. In the case of $\mathrm{V}$, an agent would conceive of $t$ being present where $t$ does not originate from $\mathrm{M}$, rather it originates from $M^{*}$. Since the kind of conceiving involved would be primary, we would be operating with the primary intensions of $t$ and $\mathrm{M}$ and $\mathrm{M}^{*}$, rather than with their secondary intensions. A static model of the conceived state of affairs would simply involve an agent reflecting on the proposition $t$ could have come from $M^{*}$ rather than $M$. A dynamic model of the conceived state of affairs would involve an agent running a simulation in their imagination of $\mathrm{M}^{*}$ being carved from $\mathrm{T}$, and then into $t$. In the case of $\mathrm{U}$, an agent would conceive of animals resembling unicorns in the relevant respects. But the general idea would be that by conceiving of a scenario or situation in which $\mathrm{U}$ and $\mathrm{V}$ are true, we can come to be justified in believing that $\mathrm{U}$ and $\mathrm{V}$ are true.

On CG the basic idea is an agent is justified in believing $\mathrm{U}$ or $\mathrm{V}$ just in case were they to counterfactually assume the relevant proposition they would not be led to a contradiction. In the case of $\mathrm{V}$ an agent would assume that $t$ originates from $\mathrm{M}^{*}$, and were they not to detect a contradiction they would be justified in believing $\mathrm{V}$. In the case of $\mathrm{U}$, an agent would assume that animals resembling unicorns of the myth are present, and were they not to detect a contradiction they would be justified in believing $\mathrm{U}$.

Notice, that in both cases, I have not argued that $\mathrm{V}$ and $\mathrm{U}$ are known or justified on the basis of either MR or CG. Rather, I have briefly sketched how it is that one would approach coming to know or acquiring justification for believing $\mathrm{V}$ or $\mathrm{U}$ on the basis of these views. It is important to note that if the essentiality of origins and the essentiality of kind membership are part of what we use to construct a scenario, in the conceivability case, or to evaluate a counterfactual, in the imaginability case, we might not be able to claim that there is a scenario in which $\mathrm{V}$ or $\mathrm{U}$ are true or that $\mathrm{V}$ or $\mathrm{U}$ do not lead to a contradiction on the assumption that they are true. All that has been shown here so far is how we might go about gaining justification for $\mathrm{V}$ and $\mathrm{U}$ through conceivability and counterfactual reasoning in imagination.

Let $\Delta$ stand for either MR or CG, and also connote the tag ' $\Delta$-theories' with reference to the two options Chalmers and Williamson provide in the epistemology of modality. With respect to $\Delta$-theories, the following argument, called the core argument against $\Delta$-theories, can be formulated.

1. $\Delta \rightarrow \mathrm{S}_{5}$

2. $\neg \mathrm{S}_{5}$

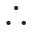

3. $\neg \Delta$

(1) is the main premise that needs to be justified in the case of both MR and CG. In the case of MR, Vaidya (2008) argues on the basis of MM, as follows.

MM: The space of logical modality is co-extensive with the case of metaphysical modality. 

i) $\mathrm{MR} \rightarrow \mathrm{MM}$
ii) $\mathrm{MM} \rightarrow \mathrm{S}_{5}$
iii) $\neg S_{5}$ $\therefore$
iv) $\neg \mathrm{MR}$

The argument against $S_{5}$ is of course the Salmon-Vaidya argument against $\mathrm{S}_{4}$ based on V. In the case of CG a similar argument can be made, except that (i) and (ii) would have to be replaced by:

$$
\text { (W) CG } \rightarrow \mathrm{S}_{5}
$$

However, there is a disanalogy between Chalmers and Williamson with respect to the core argument. Vaidya (2008) argues for (i), and Chalmers (1999) explicitly endorses (i). By contrast, Williamson does not explicitly endorse (W) in the context of the epistemology of modality as developed in Williamson (2007). Although Williamson (2013) ${ }^{5}$ does defend $S_{5}$, it should be noted that his mutual endorsement of CG and $S_{5}$ across (2007) and (2013) could not lead one to conclude that (W) holds. More importantly, what is crucial is whether the proof of the logical equivalence in $\mathrm{CG}$ requires assuming $\mathrm{S}_{5}$. If the only way to prove that it is possible that $p$ is logically equivalent to were it the case that $p$ it would not be the case that a contradiction follows depends on assuming that there is only one space of possible worlds on which all worlds are accessible to each other, than there would be reason to hold (W).

In what follows my interest here is in developing a problem that rests on three claims.

(R) In order to know which system of modal logic, $\mathrm{T}, \mathrm{B}, \mathrm{S}_{4}$, or $\mathrm{S}_{5}$ is correct we need to rely on modal intuitions.

(I) Modal intuitions, such as $\mathrm{U}$ and $\mathrm{V}$, are inconsistent with $\Delta$-theories.

(D) If $\Delta$-theories are false, then $\mathrm{U}$ and $\mathrm{V}$ are unknowable.

\section{Explanation of the Problem}

Some will object to (R) because they hold that modal intuitions play no substantial role in identifying which of the many systems of modal logic is correct. However, it appears that while it is plausible to argue that in some cases modal intuitions play no role, it appears impossible to hold it in every case. For example, the system $\mathrm{T}$ can be argued to make nothing more than an analytic claim about 'necessity' understood either logically, metaphysically, or epistemically. The claim is simply that whatever is necessarily true, is true. To deny this borders on incoherence. Consider (a) and (b):

a) It is necessary that bachelors are unmarried males, but it isn't true.

b) I believe that Zuleica plays soccer, but it isn't true. 
Just as the concept of belief reveals that (b) is prima facie nonsense. The concept of necessity reveals that (a) is prima facie nonsense. However, the argument made here cannot be extended to the case of $\mathrm{B}, \mathrm{S}_{4}$, and $\mathrm{S}_{5}$. Consider (c), (d), and (e):

c) It is necessary that bachelors are unmarried males, but it is not necessarily necessary that bachelors are unmarried males.

d) It is possibly necessary that bachelors are unmarried males, but it isn't true that bachelors are unmarried males.

e) It is possibly necessary that bachelors are unmarried males, but it isn't necessary that bachelors are unmarried males.

Consideration of $(c)-(e)$ reveals that one must go beyond mere conceptual truths or direct understanding. I hold that while (b) rests on a conceptual truth about necessity, (c), (d), and (e) do not. As a consequence knowledge of B, $S_{4}$, and $\mathrm{S}_{5}$ requires consideration of the metaphysics of modality, some of which rests on modal intuitions concerning kinds or a substantial scientific theory of kinds.

(I) is also controversial. Roca-Royes (2006) has argued that one can use a modified version of Peacocke's Unified Modal Extension Principle to show that $\mathrm{V}$ can be made consistent with $\mathrm{S}_{4}$. The basic idea is that rather than holding that $\mathrm{M}$ is the piece of wood from which $t$ originates, we simply hold that $M_{1} \ldots M_{n}$ is the range of pieces of wood from which $t$ originates. As a consequence, what is necessary is that $t$ originates from the range $\mathrm{M}_{1} \ldots \mathrm{M}_{\mathrm{n}}$ and not $\mathrm{M}$. That is rather than let $\mathrm{V}$ stand as a counterexample to $\mathrm{S}_{4}$, make it the case that because social kinds can tolerate flexibility at their origin, the Unified Modal Extension Principle requires us to select the range, instead of the particular slice in the range that is M. Roca-Royes's proposal is quite engaging and powerful. However, it would only apply to the Salmon-Vaidya argument, and not to the case of the Dummett-Walters argument. So, (I) is surely controversial. But when we push harder on this case what is revealed is that there are two options: either deny the intuition concerning the flexibility of origins or deny the inconsistency of the intuition with $\mathrm{S}_{4}$.

(D) is not as controversial as either (R) or (I). Rather, what (D) brings to the forefront is the epistemic question about justification. More importantly, it invites us to start inquiring into what other options outside of $\Delta$-theories are available for coming to know modal truths. Let me close this section by considering another option, which I don't believe gets us out of the problem.

Consider Lowe's (2012) proposal for how we come to know modal truths. On his account we come to know what is necessary by way of essence. This sets up a deductive model for arriving at knowledge of possibility.

A knows that $E$ is the essence of $x$.

A knows that if $E$ is the essence of $x$, then $\square E x$.

A knows that $F$ is inconsistent with $E$.

If $F$ is inconsistent with $E$, then $\neg \diamond F x$.

$\therefore$

$\neg \diamond F x$. 
There is something compelling about this strategy that makes it attractive in contrast to conceivability-based reasoning or counterfactual reasoning. The basic idea is that we know that $\mathrm{U}$ and $\mathrm{V}$ are true simply by first coming to know the essence of the relevant objects involved, such as unicorns and tables. Once we know the relevant essential properties we are in a position to deduce whether $\mathrm{U}$ or $\mathrm{V}$ are true. However, as is clear by the nature of the approach, this setup pushes the question back further. Rather than asking how we know what the modal properties of an object are we are now asking: what are the essential properties of the object? However, we face two problems on this approach. First, it could be that in all cases essence grounds modality, but in some cases we come to know about modality through some route other than through deduction from essence. Second, even if we do know about modality through essence: How do we sort the essential properties from the merely accidental? Arguably, the latter question is just as difficult as the question: how do we sort the possible from the necessary. Lowe argues that knowledge of modality does not depend on imagination, conceivability, or intuition. But then what does it depend on? He argues that it depends on grasp of essence. But this just leaves us in the dark on the whole matter. One might simply concede the structural point: knowledge of modality depends on knowledge of essence, but then argue that intuition in conjunction with knowledge of real definitions gives us knowledge of essence. Why should we trust our intuitions of essence? And: Which intuitions should we trust?

\section{Reflective Equilibrium and the Conservative Approach to Intuition}

A natural answer to both of the questions raised in the last part of the previous section, and concerning the whole project of selecting the correct modal logic, comes from Nelson Goodman (1955). He famously says the following about how the rules of deductive inference are justified:

I have said that deductive inferences are justified by their conformity to valid general rules, and that general rules are justified by their conformity to valid inferences. But this circle is a virtuous one. A rule is amended if it yields an inference we are unwilling to accept; an inference is rejected if it violates a rule we are unwilling to amend. The process of justification is the delicate one of making mutual adjustments between rules and accepted inferences; and in the agreement thus achieved lies the only justification needed for either. (Goodman 1955: 67)

Surely if this method works in the case of deductive inference, it can be made to work in the case of identifying the correct modal logic. For example, $\mathrm{K}$ and $\mathrm{T}$ seem to be undeniable, while $\mathrm{B}, \mathrm{S}_{4}$, and $\mathrm{S}_{5}$ are all questionable. We would hope that the identification of the correct modal logic could be achieved on the basis of the greatest coherence between our modal intuitions and other principles of logic. But this pushes out the question that really needs to be addressed, and which has been looming since the beginning: Which modal intuitions should we trust? Skeptics would say none. Liberals would say all. But I think a more 
promising approach is available between the skeptical and the liberal position. That approach takes us to a conservative picture of which intuitions should form the data from which we attempt to identify the correct modal logic.

Let me begin articulating the conservative approach through a rough distinction between two kinds of modal claims. ${ }^{6}$

Ordinary modal claims include the following:

i) It is possible for an unbroken table to be broken.

ii) A chair located in one part of a room could be located at another part of the room.

iii) A person born as a non-twin could have had a twin.

iv) A table $t^{*}$ carved from $\mathrm{M}^{*}$, distinct from $t$ carved from $\mathrm{M}$, could have been made from $\mathrm{T}$.

Extraordinary modal claims include the following:

v) There could have been unicorns.

vi) Zombies (creatures physically identical to humans, but lacking consciousness) could have existed.

vii) There could be a perfect duplicate of $f$.

viii) A table $t$ which is carved from a hunk of wood $M$ taken from tree $T$ could have been carved from a hunk of matter $\mathrm{M}^{*}$ just slightly different from $M$ and still been the very same table.

Now the jarring, but crucial part: No precise distinction between the ordinary and the extraordinary can be drawn. To seek an account between the two with exact necessary and sufficient conditions is to engage in a philosophical folly. However, some comments about the items on both lists can be made, and also some structural features of the distinction can be noted. I will begin with a comparative commentary, and then move into discussion of the structural features.

Notice that (i) and (ii) concern ordinary objects in ordinary situations. They also are in the penumbra of modal judgments we often make. We think about whether a table can break and under what circumstances it might break when purchasing one. And likewise we think about where a chair could be located in a room relative to other furniture when we are thinking about arranging things in a room. By contrast, (v) and (vi) are statements that, if we believe to be possible, are likely based on stories that contain descriptions of such creatures. While these stories can involve highly creative descriptions, they are often not based on, nor contain the kinds of descriptions that would be necessary for one to have even a reasonable belief in the existence of such things. The point can be more carefully attended to by noting that within the genre of science fiction it is well known that the stories are successful when they have the right blend of fantasy and science.

6 There are many papers in which the distinction between ordinary and extraordinary (perhaps the use of different words) is appealed to. Van Inwagen (1998) serves as one historically important place, more recently, Bueno \& Shalkowski (2014) serves as another place. 
Notice that (iii) and (vii) look similar with respect to duplication. However, the claim in (iii) is quite innocuous and in the realm of the ordinary, while (viii) appearing innocuous, is actually unclear. In (iii) we know what processes account for a twin to be born. In (vii) we don't know what it would mean for $f$ to have a perfect duplicate by way of a process. We know what perfect duplicate is, but we don't know what process could bring it about.

Notice that (iv) and (viii) also look similar. But again there is a key difference. In (iv) the claim is that another table looking similar to the original table could have been made from matter just slightly different from the matter that was used to create the original table. The claim in (viii) is about one and the same table having a modal property that of being possibly created from matter distinct from that from which it was originally created. The distinction is that (iv) is what could be created from the tree T by way of a process, while (viii) is about a process and identity. Moreover, (viii) is stronger than (iv).

Now that we have some details about the list down, we can also note some structural features of the distinction. First, and foremost, the distinction between ordinary and extraordinary modal claims changes over time as we learn more about the actual world both in science and mathematics. What is legitimately believed to be possible or impossible at one time can later be deemed impossible or possible simply through consideration of the relevant science and mathematics. This meta-modal-epistemic insight is grounded in experience of the actual world as discoveries are made in mathematics and science. For brevity I mention only two examples.

At one period of time in mathematics it was thought that there is only one size of infinity. Then G. Cantor's argued that the real numbers could not be put into a one-to-one correspondence with the natural numbers. At one period of time in physics it was thought that the speed at which an object was moving could not effect time. Then A. Einstein argued that an object moving close to speed of light would slow time.

Second, the distinction between the two groups does not rest on the phenomenology of reflection. It is not that ordinary modal propositions feel more certain on reflection than extraordinary modal propositions. For example, consider the counterpossible: if the number 2 were the number 3 , then ' $2+2$ $=6$ ' would be true. The antecedent of the conditional is false in every possible world, since it is impossible for 2 to be 3 . The phenomenology of reflection on the truth of the counterpossible is as strong as the phenomenology of reflection on the truth of the unrealized possibility: although Miranda does not have a brother, she could have had a brother. However, the closest possible world in which the counterpossible is true can be argued to be much farther away from the actual world as the unrealized possibility claim. Thus, some extraordinary modal claims may have the same phenomenal reflection strength as simple ordinary modal claims about unrealized possibilities. In addition, although more controversial, some modal theorists might argue that the claim that unicorns could have existed is as phenomenologically certain as the claim that a table that is unbroken could have been broken.

Third, ordinary propositions do not distinguish themselves from the extraordinary in virtue of how distant they are from the actual world. For the very 
notion that $w_{1}$ is more distant from @ than $w_{2}$ is riddled with thorny problems, two of which include the problems caused by the existence of impossible worlds and the relativity of the similarity relation across worlds. In addition, the counterpossible discussed above, is potentially case of a proposition that is distant from the actual world, yet knowable. ${ }^{7}$

Now if the distinction is granted, then the approach to selecting a modal logic I believe we should adopt is the conservative approach, CA.

CA: Ordinary modal propositions form the data from which a modal logic should be brought into alignment through reflective equilibrium, and not extraordinary modal claims.

CA has two primary benefits. First, while it is conservative as to which data it allows in, the approach it takes to which modal logic we are justified in believing in at a given time, it is also permissive with respect to change. Were an extraordinary modal proposition to find additional support it would then become an ordinary modal proposition, which in turn could force an adjustment as to which modal logic we should accept. Second, it has the benefit of focusing our attention on understanding theories, which in turn have modal consequences, rather, than focusing on modal intuitions based merely on their phenomenology. The second benefit does not aim to downplay the importance of the phenomenology of modal intuitions. For the phenomenology of modal intuitions has a role to play in an account of which modal logic we are to accept. ${ }^{8}$ Moreover, the focus of the second point is to push our attention to other areas of mathematical and scientific inquiry that may corroborate our intuition. Just as science and mathematics are blind without metaphysics, metaphysics without science and mathematics is empty. As a consequence, the debate over the significance of Dummett's argument and Salmon's argument is that they rest on extraordinary intuitions, intuitions whose weight is significantly weak with respect to the project of determining the correct modal logic. More weight ought to be given to theoretical conditions about modal logic. One key exemplification of this weighting issue between intuition and theoretical considerations is tackled by Williamson (2013) in his articulation and defense of necessitism.

\section{The Debate over Necessitism}

Williamson (2013) defines necessitism and contingentism as follows:

Call the proposition that it is necessary what there is necessitisim, and its negation contingentism. In slightly less compressed form, necessitism says that

7 It would be inappropriate of me not to mention the excellent work of Kment (2014) on defining the similarity relation across worlds and discussing how comparison and weighting can be done across worlds. Nevertheless, we cannot conclude from the fact that an intuitive modal proposition is a close modal proposition, nor that a distant modal proposition is a counterintuitive proposition.

8 For an excellent theory of how the phenomenology of intuition plays a role in justifying our beliefs see E. Chudnoff's perceptual theory as articulated and defend in his (2013). 
necessarily everything is necessarily something; still more long-windedly: it is necessary that everything is such that it is necessary that something is identical with it. In slogan: ontology is necessary. Contingentism denies that necessarily everything is something. In a slogan: ontology is contingent. (Williamson 2014: 2)

As an example of a proposition that necessitism and contingentism will differ over, Williamson give the example of (C).

C: This coin, which actually exists now, could have failed to exist.

According to contingentism (C) is true, because what there actually is could have failed to be. According to necessitism (C) is false. Taking note of the obvious jarring content of necessitism, Williamson raises an obvious question about it with a corresponding argument for a specific conclusion.

Why take necessitism seriously? Isn't it just obvious that many things, such as the coin, could have not been? [...] If a philosopher produces a clever theoretical argument for necessitism, we may learn much from diagnosing the fallacies in it, just as we may learn much from diagnosing the fallacies in a clever argument for radical skepticism, but in each case are we not entitled to confidence in advance that the argument will indeed be fallacious. (Williamson 2014: 5).

In the prior section I argued that we should not take extraordinary intuitions about modal maters seriously in selecting a system of modal logic. How does that claim interact with the prospects of Williamson's extended defense of the, admittedly, counter-intuitive thesis of necessitism? Contrary to how things might seem, the claim that we should only consider ordinary modal intuitions does not yield even a prima facie argument against necessitism. To draw out the reason why consider $(\mathrm{C})$ alongside $(\mathrm{N})$ :

(C): This coin, which actually does exit, could have failed to exist.

(N): This coin, which actually does exist, could not have failed to exist.

Is $(\mathrm{C})$ somehow more intuitive as a modal proposition than $(\mathrm{N})$ ? The question generally attracts the answer that $(\mathrm{C})$ is far more intuitive than $(\mathrm{N})$. On the basis of the greater attraction of $(\mathrm{C})$ over $(\mathrm{N})$ some may be inclined to argue as follows:

1. Intuitive modal propositions are ordinary modal propositions.

2. Ordinary modal propositions must be considered in investigating systems of modal logic.

3. (C) is an intuitive modal proposition.

4. So, (C) should be taken seriously in investigating systems of modal logic, and since (C) is inconsistent with necessitism, in advance of considering the arguments for it, we can be confident that it should be rejected.

By unpacking the argument this way I believe we can expose a cognitive blind spot in our modal theorizing. (1) is false. The intuitive and the ordinary do 
not over lap. Some intuitive propositions are non-ordinary, even if they fall short of being extraordinary. Some unintuitive propositions are ordinary, even though they are unintuitive. Since our concern is with the unintuitive that might turn out to be ordinary, consider an example from mathematics, the Banach-Tarski Theorem (BTT).

(BTT): Given a solid ball in 3-dimensional space, there exists a decomposition of the ball into a finite number of non-overlapping pieces (i.e. disjoint subsets), which can then be put back together in different ways to yield two identical copies of the original ball.

For the purpose of simplification, and to make explicit the modal claim, we can reduce (BTT) to $(\mathrm{B})$.

(B): Where B is a solid ball in 3-dimensional space it is possible to convert B into two identical copies of itself.

(B) is counterintuitive, but it is not extraordinary. While the content of the claim is counterintuitive, the existence of a mathematical proof of it puts it in the realm of ordinary modal propositions. Ordinary modal propositions track established scientific and mathematical theories and propositions deducible from them. While it is true that $(\mathrm{N})$ is unintuitive, it is no more unintuitive than $(C)$. What is relevant is whether there are scientific and mathematical facts that also play a role in justifying our belief in either $(\mathrm{C})$ or $(\mathrm{N})$. Take the analogy with (B) again. (B) is counterintuitive, but this does not mean we should reject it. Rather, because we also have a proof of it, we should disregard the counterintuitive nature of (B) and seek another explanation for why we think that (B) is counterintuitive. It could be that (B) is like a Müller-Lyer illusion, even though we believe the lines to be the same length we cannot but seem them as being of different lengths. Likewise, $(\mathrm{N})$ is counterintuitive, but in light of the sustained arguments that Williamson has offered in defense of $(\mathrm{N})$, it maybe that we have to look at $(\mathrm{N})$ as a counterintuitive claim that rests on significant logical and metaphysical theorizing and proof. Our continued belief that $(\mathrm{N})$ is counterintuitive may be nothing more than an illusion similar to what is at play in the case of (B) and the lines of a Müller-Lyer diagram.

\section{References}

Chalmers, D. 1999. Materialism and the Metaphysics of Modality. Philosophy and Phenomenological Research 59: 473-496.

2002. Does Conceivability Entail Possibility? In T. Gendler and

J. Hawthorne (Eds.) Conceivability and Possibility. Oxford University Press.

Chudnoff, E. 2013. Intuition. Oxford University Press.

Dummett, 1993. Could There Be Unicorns? In his The Seas of Language. Oxford University Press: $328-348$.

Goodman, N. 1955. Fact, Fiction and Forecast. Harvard University Press. 
Kment, B. 2014. Modality and Explanatory Reasoning. Oxford University Press.

Lowe, E. J. 2012. What is the Source of Our Knowledge of Modal Truths? Mind 121. 484: 919-950.

Roca-Royes, S. 2006. Peacocke’s Principle-Based Account of Modality: „Flexibility of Origins" Plus $S_{4}$. Erkenntins 65: 405-426.

Salmon, N. 1989. The Logic of What Might Have Been. The Philosophical Review 98: 3-34.

Salmon, N. 1993. This Side of Paradox. Philosophical Topics 21: 187-197.

Vaidya, A. 2008. Modal Rationalism and Modal Monism. Erkenntins 68: 191-212.

Van Inwagen, P. 1998. Modal Epistemology. Philosophical Studies 92: 67-84.

Walters, L. 2014. The Possibility of Unicorns and Modal Logic. Analytic Philosophy

Williamson, T. 1990. Identity and Discrimination. Blackwell Publishers.

- 1998. Bare Possibilia. Erkenntnis 48: 257-273.

2007. The Philosophy of Philosophy. Oxford: Wiley-Blackwell.

2013: Modal Logic as Metaphysics. Oxford: Oxford University

Press. 